\title{
The successful root canal oxymoron
}

\author{
Ron Carlson* \\ Carlson Bridge Technologies, Inc., Private Enterprise, Hawaiia, USA
}

Driving the continuance of endodontology — so called study of modern root canal therapy-is the ongoing false claim that one can meet a "successful sterile root canal." As stated this is a mental construct at odds with itself; one has never met, nor ever will, a "successful sterile root canal."

This is no empty assertion. Climb out of the academic ruse and see the light, the Truth of the matter.

Consider physiology-the biological processes of the life of the odonton. An Odonton-its corollary bone counterpart Osteon-is a living unit and composted of the bone around the tooth and the soft tissue attaching the tooth itself-the jaw segment bone. We illustrate that dynamic relationsip in Figure 1.

\section{Basic living tooth anatomy}

\section{Inner dentine layer}

The basic structure of an ODONTON is much like that of a tree with the enamel covering the dentine as would the bark cover the underlying cambium layer of the tree, the bone being the terrain or soil (Figure 1).

As a dental surgeon of close to 50 years I have witnessed great suffering and sickness on the part of those who have chosen the way of gangrene-root canal therapy. Consider for a moment the salient question in this day and age, regardless of what other professionals advocate at to the retention of "dead tissue," gangrenous tissue; is this dead tissue, the root cadaver, healthful for the sterile internal environment of the human body? No, it is not!

The advocacy of root canal therapy by the American Association of Endodontists https://www.aae.org is the organized dis-information site based upon misrepresentations, wishful thinking. Un-refutably, all root canals harbor bacteria, viruses, molds, fungus, and endotoxins to varying degrees for the life of the root canal-a non-sterile environment at best.

Ask your doctor, "can you guarantee the sterility of my root canal?" He will answer most probably by avoiding an answer and offer that the disinfection protects against future problems. Then he will glibly state that, "properly done we have a $98 \%$ success rate."

He has coaxed you into the "success rate obfuscation argument." Success rates are opinions, not facts, about how long a root canal may seemingly work for you without symptoms such as pain, swelling, breakage, etc. There is great controversy here to be sorted out in truthful logic.

Be assured, without sterility of the internal part of the tooth, pulp chamber, dentine, ligaments and bone your root canal is a "septic tank" for the infusion of infected materials-then on to the blood and lymphatic systems disseminating micro-organisms and endotoxins throughout your entire body.

This is unquestionably the fact upon which to stand.

So beware of the trap "we have a $98 \%$ success rate in root canal therapy" bellowed by the dental professional. This sidesteps the question, "is there success with non-sterility?" Success with sterility is impossibility at this time. We offer Figure 2 to emphasize the truth in a visual manner.

The tooth in Figure 2 had no symptoms and was deemed a successful root canal by the treating dentist. Upon removal of the dead tooth we note a root end abscess, this is a pus sack, graphically characterized in Figure 3.

The sack at the root tip is a reservoir, septic tank Figure 3, for the effluents from the root canal on their way into the circulatory and lymphatic systems eventually being purified by the kidney.

Extracted molar root canal tooth with all porcelain crown that had for years given the patient no discomfort. The tooth in view has soft tissue pus sacks that are attached to the root tips and have dental probes pointing to pathology known as radicular abscess or cysts. More than likely this condition was created by the radical cutting of the tooth and dental lymph bleeding.

The key point in our discussion is be not entrapped into the "success rate debate"- this is be-sides the point. Ask yourself do you wish something un-sterile in your tissues, septic tank, as a potential source of inflammation and infection? The dental organ, Odonton, is a living entity as are your eyes, ears, thyroids, para-thyroids, kidneys, adrenal glands and other organs. To see your teeth as nothing more than an expedient and salvageable by "root canaling" is a danger being exposed by more and more enlightened humans understanding that the human physical body is a sterile space for life to live.

Until 1970 it was "thought" that sterility was possible and that one could hermetically seal or mummify a dead tooth, but that was given up when research conclusive found that sterilization of a dead tooth was impossible. Now it is the "disinfection game" not sterility Figure 3.

*Correspondence to: Ron Carlson, Carlson Bridge Technologies, Inc., Private Enterprise, Hawaiia, USA, Tel: 01-808-735-0282; E-mail: ddscarlson@ hawaiiantel.net

Received: November 02, 2018; Accepted: November 22, 2018; Published: December 26, 2018 


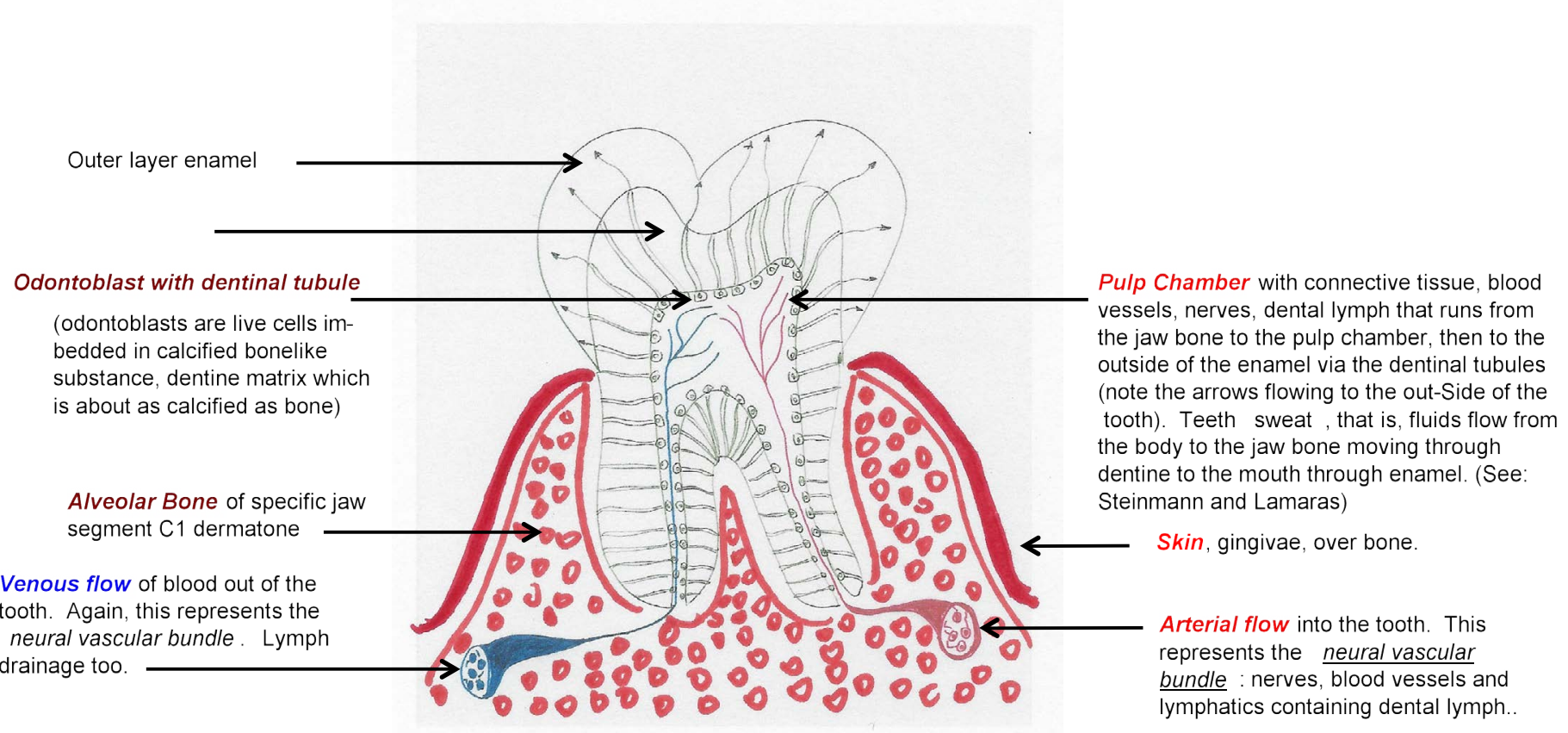

Figure 1. Basic living tooth anatomy

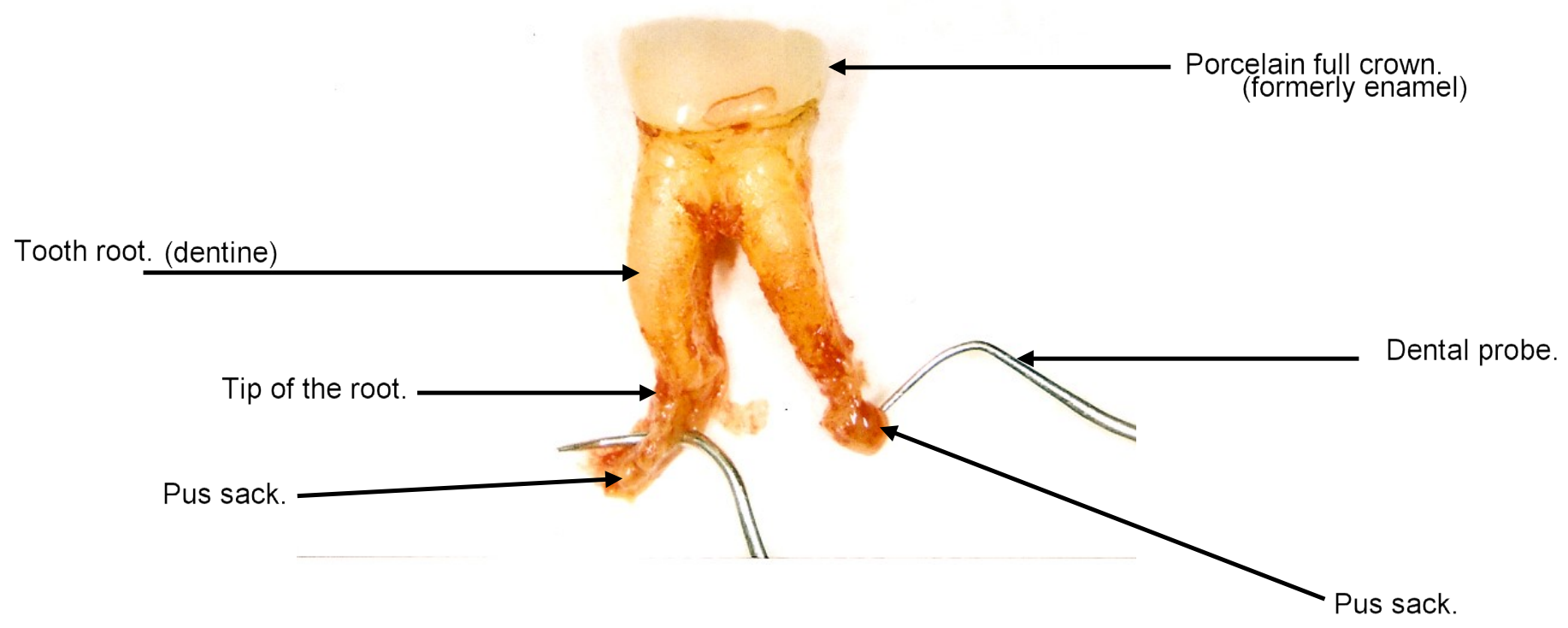

Figure 2. Tooth anatomy 


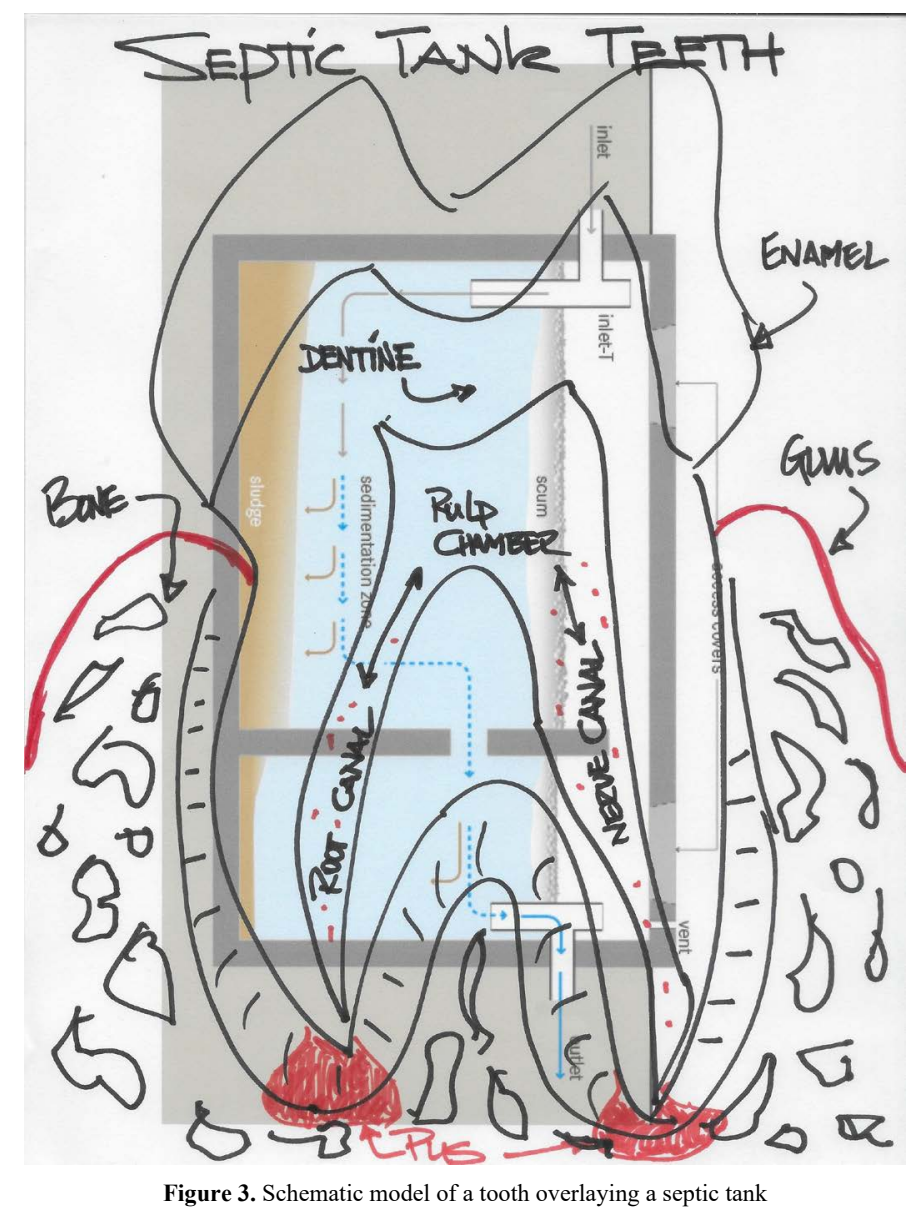

Copyright: ( 92018 Carlson R. This is an open-access article distributed under the terms of the Creative Commons Attribution License, which permits unrestricted use, distribution, and reproduction in any medium, provided the original author and source are credited. 